\title{
Silicosis - 10000 gold miners getting set to sue
}

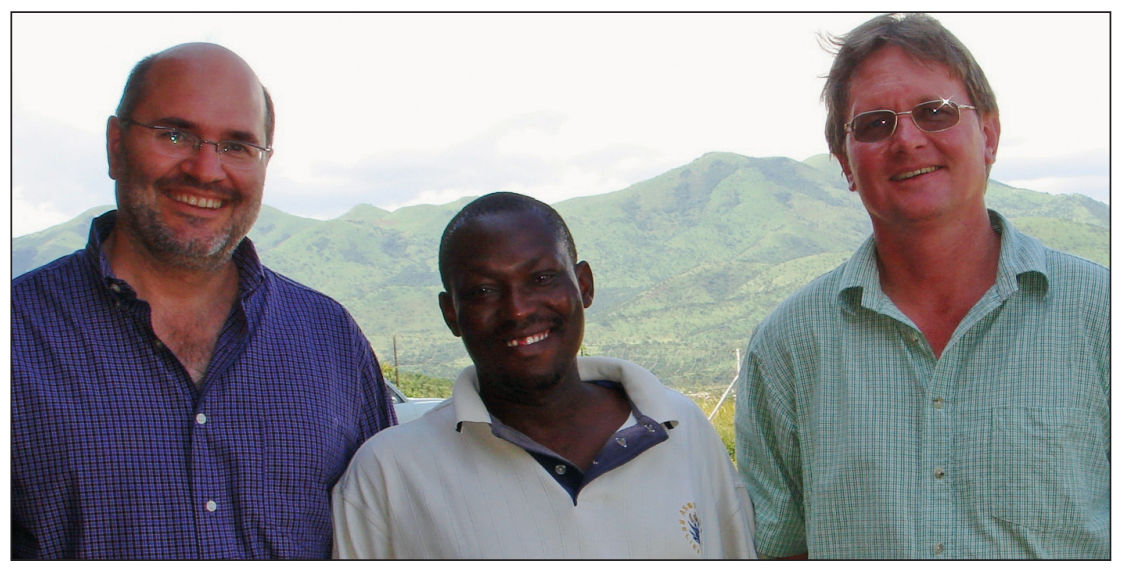

$(L-r)$ Cape Town medical specialist in public health, Dr Jim Te Water Naude, gold miner Patrick Shiba and class action lead lawyer Richard Spoor.

Tagged as victims of 'the world's biggest, longest running industrial disaster; dwarfing Chernobyl', 10000 known silicosis-affected southern African gold miners are finally set to negotiate a payout that could induce a painful paroxysm of shareholder coughing across the Johannesburg Stock Exchange.

Richard Spoor, the lead lawyer who a year ago secured a landmark Constitutional Court ruling allowing lung-diseased miners to sue their employers for substantial damages (under common law), said the application for certification of a class action, plus a process for establishing liability, would come before the South Gauteng High Court 'within months'.

\section{This is something completely new and we want the mining companies' input as to} whether they think it's fair and appropriate. At the core of our position is that if we don't deal with it on a collective basis, people will not get justice.

Spoor has out-of-court settlements from asbestos mining houses totalling R1.1 billion since 2003 , all of which precluded a ruling on the constitutionality of archaic mining legislation that in some cases limited medical incapacity payouts to just R1 000 for every year worked. The latest litigation is virgin legal territory and may well bring substantial financial relief to those injured or to relatives of those killed by mining-acquired silicosis.

After meeting his senior advocates on 9 April this year, Spoor told Izindaba that the final form of the application would depend on the responses of the individual defendants, AngloGold Ashanti, Gold Fields, Harmony Gold (South Africa's biggest gold miners), and smaller producers, DRD Gold.

'We want to discuss the process with them. Our court application includes a recommendation to the judge on how the matter should be dealt with. This is something completely new and we want the mining companies' input as to whether they think it's fair and appropriate. At the core of our position is that if we don't deal with it on a collective basis, people will not get justice. It's a crazy notion to think that somebody in some remote Transkei, Lesotho or Mozambican village can bring a civil action to recover damages - that just won't happen; that's why a class action is appropriate.'

While each individual miner will have to prove damages (via an independent medical panel), the basic principles governing any award will be what the South Gauteng High Court adjudicates on, paving the way for the setting up of a Silicosis Trust from which funds would be disbursed. Actuaries will use the best epidemiological data to table individual company award amounts (how many cases, of what severity, ages, life expectancy and geographical information per respondent gold mine).

Based on his previous out-of-court settlements with asbestos mining companies (Gencor, Hanova, Eternit, et al.) in 2003 and 2006, Spoor is confident that the trust fund model can be sufficiently enlarged and administered to handle what currently stands at 15 times as many victims.

\section{Mining executives take a deep breath}

A 2009 collaborative study by the University of the Witwatersrand and University College, London, estimates there to be 288000 cases of compensable silicosis in South Africa, which would put that unpaid liability at R10 billion in 1998 values (R27 billion in today's values). This gives some indication of what even lesser settlements could do to shareholder values on the Johannesburg Stock Exchange and how the ConCourt ruling must be focusing the minds of senior mining company executives.

Spoor said that his estimate was of 'at least' 200000 workers needing followup, screening 'and hopefully, treatment'. Identification of legitimate claimants is complicated by geography, awareness and a dysfunctional public health system but the numbers are already growing in their

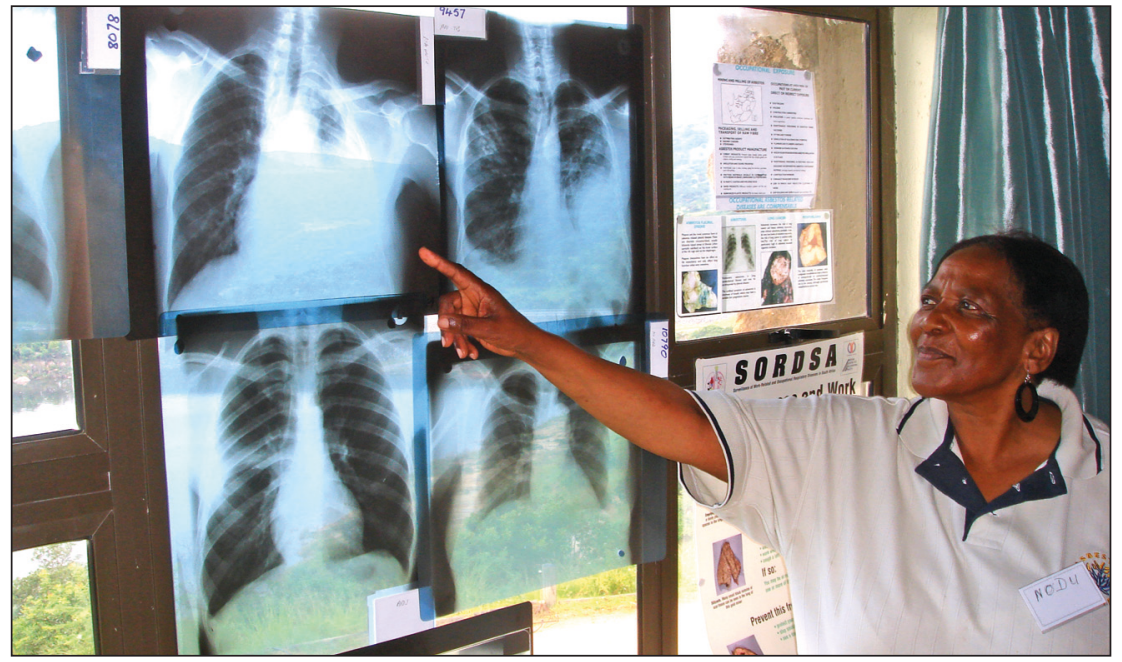

Sister Fikile Nolokwe of the Asbestos Relief Trust explaining lung impairment to a community group that included miners prior to their 2004 awards. 
thousands every year (more than 7500 in Lesotho and over 2000 in the Eastern Cape at the time of going to press). While there had been no formal engagement of the gold mines at the time of writing, Spoor said there was 'a fair amount of sounding out - we have a consultant encouraging thinking and discussion to create a high-level awareness for the company to make the right decisions'.

\section{ConCourt ruling the 'tipping point' for claimants}

The tipping point came in March last year when Spoor asked the Constitutional Court to declare unconstitutional a section in the workman's compensation legislation prohibiting workers from suing their employers. The case he used was that of a single R2.5 million claim turned down by both the High Court and the Court of Appeal on the grounds that the State had set up a compensatory system and that the quid pro quo was that this precluded the possibility of civil suits. ${ }^{1}$ The AngloGold Ashanti miner, Thembekile Mankayi (who died of lung disease two weeks before the ConCourt ruling), was laid off for R16 000 (representing just over R1 000 for every year he had worked). His payout was made in terms of the Occupational Diseases in Mines and Works Act (ODIMWA), which specifically and exclusively caters for (in limited terms) sick miners. AngloGold cited the relevant section of ODIMWA which clearly states that compensable diseases are prohibited under the Workman's Compensation Act. The ConCourt upheld Spoor's contention that both laws trampled on Mankayis common law rights.

Ironically cabinet resolved as far back as 1998 to re-align the two acts, but disagreement between government and the Chamber of Mines over who would pay the costs associated with lung-diseased mineworkers quickly snuffed out the initiative. Government was reluctant to carry financial responsibility for laws it had no hand in making while the mines cried foul over potentially carrying the financial can for mines that had stopped operating. Spoor put it succinctly, 'Basically the laws acted as a subsidy to the industry. The real cost is borne by the workers, their families and the public health system. The "polluter pays" principle should apply to occupational health - but it doesn't.'

\section{Track record of medical panel}

Cape Town medical specialist in public health, Jim Te Water Naude, one of Spoor's

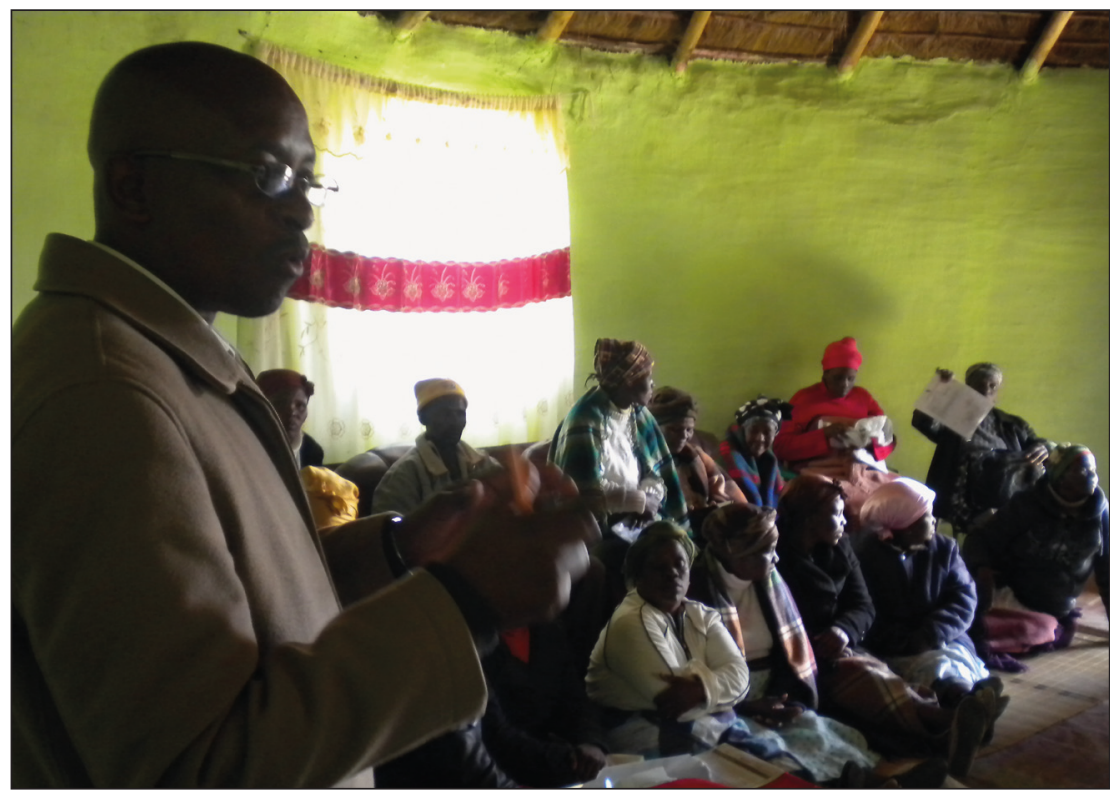

Former mineworkers in rural Lesotho being briefed about the class action. large team currently assessing claimants in preparation for the South Gauteng Court application, gave some idea of how 'recruitment' might go by citing previous experience. He said his occupational medicine panel screened 14000 ex-asbestos miners over the last 7 years, working mainly with rural GPs. Numbers peaked at 3000 people annually in 2007 before tailing off. Some 4000 were found to be compensable. Three per cent of them (420) had mesothelioma which, along with lung cancer, meant they lived on average for about a year.

The Asbestos Relief Trust (2003) and the Kgalagadi Relief Trust (2006) paid individual miners about R280 000 for mesothelioma and about R210 000 for lung cancer while severely lung-impaired workers received about R60 000 (half this for moderate or mild lung impairment).

Spoor put it succinctly, 'Basically the laws acted as a subsidy to the industry. The real cost is borne by the workers, their families and the public health system. The "polluter pays" principle should apply to occupational health but it doesn't.'

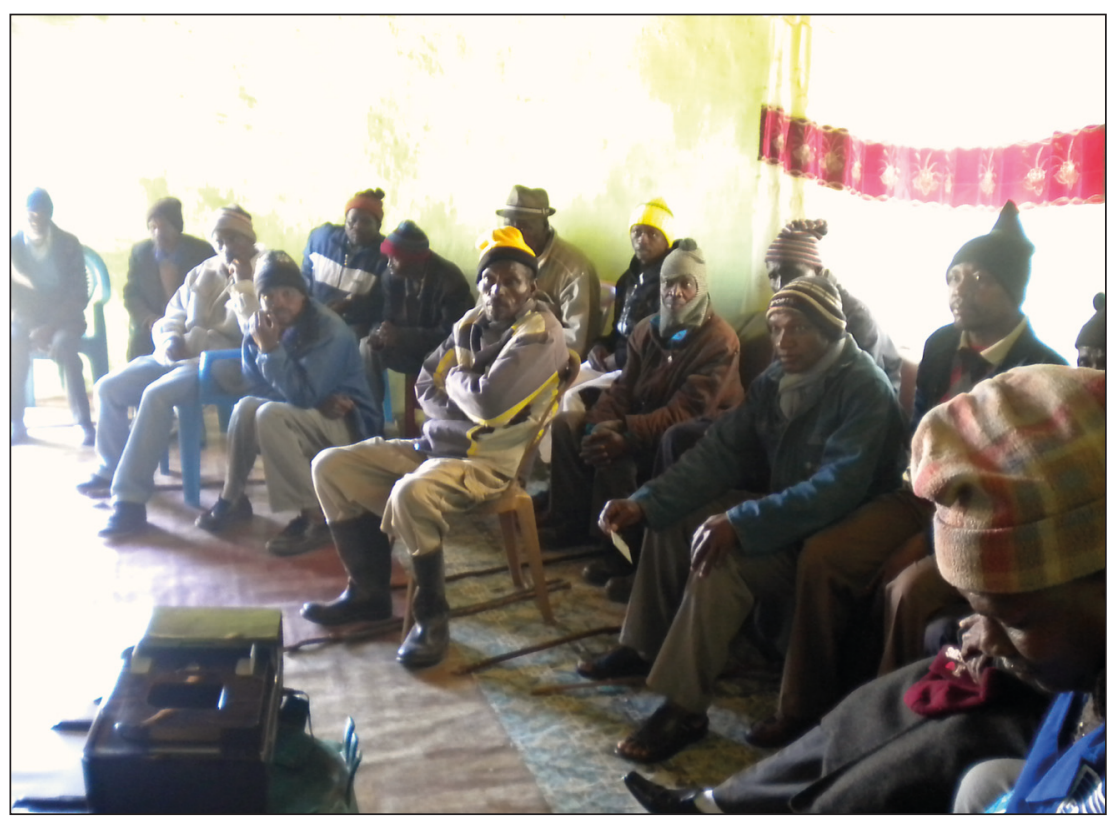

Lesotho mine workers listen attentively to a Mineworkers Development Association briefing. 
'This new case is going to be a lot of hard work with a whole lot of challenges, not the least of which is the triple epidemic on the mines of HIV, TB and silicosis. In the 90s the gold mines downsized from about 800000 workers to 400000 and the triple epidemic was (more quickly) exported to where the miners came from.' Te Water Naude said the relationship between silicosis and $\mathrm{TB}$ (owing to the macrophage system being overwhelmed by small particles of crystalline silica which comes co-compounded with gold ore) was well known.

Tina da Cruz, a legal associate of Spoor's co-ordinating claims in Maseru, said she was working with the Mineworkers Development Agency (MDA)'s Lesotho Country Office identifying potential claimants for the class action. The MDA's experience in helping the Asbestos Relief and Kgalagadi Relief trusts find former asbestos miners was proving invaluable. Field teams of former miners and lawyers created awareness among former gold miners and their communities in all districts of Lesotho while similar teams were working in the Bizana area of the Eastern Cape.

Te Water Naude said once claimants were found, the project's potential for improving public healthcare delivery was huge, citing the vastly improved Kuruman postmortem service via their efforts on behalf of asbestos victims. 'Basically we introduce a highquality management system, making sure that we communicate well upstream and downstream' (again, using private healthcare practitioners whom he said produced work of excellent quality in $85 \%$ of cases). His team was by mid-to-late April inspecting doctors' reports of 30 lung-impaired gold miners examined in Maseru and another 45 examined in Mthatha. The reports include lung function, chest radiography and a clinical evaluation.

'This is about holding people to account and once that's done you can expect substantial improvements in the workplace. Silicosis is a preventable disease. If you can kill and maim people without consequences there's obviously no reason to stop.'
In an aside, Te Water Naude said the glaring lack of continuing medical education in far flung towns was best illustrated by one GP in Prieska who attended their team's talk on asbestos-related diseases in November last year. The doctor said it was the first time in two decades he'd seen any kind of external continuing professional development activity.

\section{Major potential to boost public healthcare}

Other exciting developments included channelling PEPFAR funding (via a Yale University initiative) into their programme to help treat ex-miners with HIV and TB and looking further afield to 'see what there is beyond compensation; we want to use a future settlement to bring more synergy' he added.

Spoor said the clinical work was not an attempt to duplicate the dysfunctional state system which had no proper monitoring or surveillance, but to complement and improve it by linking into the statutory system.

He said that a 'significant' percentage of lung-impaired miners died without being diagnosed, mainly because of inadequate and inexpert postmortem services (cardiorespiratory organs need harvesting and in most cases, storing and transport). This meant that, in the main, only the organs of those who died in service (mostly black miners) and most white miners (with access to facilities) were examined.

Asked whether he'd be asking the court for an order preventing or minimising future lung impairment, Spoor said the settlement would have to make provision for wherever mine inadequacies were found. Medical monitoring and surveillance and treatment, especially for $\mathrm{TB}$, were the two major issues.

'This is about holding people to account and once that's done you can expect substantial improvements in the workplace. Silicosis is a preventable disease. If you can kill and maim people without consequences there's obviously no reason to stop. I must say the State's role as policeman of safe and healthy environments has not been much to write home about, in fact the State has proved itself incapable of policing the mines. The criminal justice system is not working, so civil accountability is the only model left to us.'
Asked how long it could take to settle the class action, Spoor said that based on his past experience, anything from 18 months to 5 years; it will all depend on the attitude of the gold mine executives and how well they recognised the inadequacy of existing compensation regimens and their moral obligations. 'It comes down to the CEO and the kinds of lawyers they get - this is not a game for bluffers.'

... the silicosis claim, when compared with famous historical mining claims in Australia and the USA, the Chernobyl and Fukushima nuclear meltdowns, and the Bhopal chemical leak in India (in terms of numbers killed and injured) 'outnumbers them all - it's basically the world's biggest and longest running industrial disaster.'

He said the role of actuaries was crucial because, if the settlement proved inadequate, claimants could 'come after me' - which is why a senior advocate was retained exclusively to ensure the payout mechanism and the kitty were adequate, providing him with what was legally termed, a 'comfort note'.

Asked what his fee was, Spoor said it could either be built into the overall settlement or established by agreement with individual clients not to exceed $15 \%$ of their award.

'As a point of reference the Gencor (asbestos) settlement was worth R450 million and my fee was R2 million for what amounted to 5 years of work. I'm saving up for a new car', he quipped.

One of his senior legal colleagues told him that the silicosis claim, when compared with famous historical mining claims in Australia and the USA, the Chernobyl and Fukushima nuclear meltdowns, and the Bhopal chemical leak in India (in terms of numbers killed and injured) 'outnumbers them all - it's basically the world's biggest and longest running industrial disaster.'

\section{Chris Bateman}

chrisb@hmpg.co.za 1. Bateman C. A better deal for lung-diseased miners? S Afr Med
J 2010;100;10:626-628. 